OPEN ACCESS

Edited by:

Minghui Cai,

Northeastern University, China

Reviewed by:

Hui Weijun,

Beijing Jiaotong University, China

Yunbo Xu,

Northeastern University, China

Libo Pan,

Jianghan University, China

${ }^{*}$ Correspondence:

Jing Liu

liujing@wust.edu.cn

Specialty section:

This article was submitted to

Structural Materials,

a section of the journal

Frontiers in Materials

Received: 21 October 2020

Accepted: 20 November 2020

Published: 08 December 2020

Citation:

Wang Z, Liu J, Huang F, Bi Y and

Zhang S (2020) Hydrogen Diffusion and lts Effect on Hydrogen

Embrittlement in DP Steels With

Different Martensite Content.

Front. Mater. 7:620000.

doi: 10.3389/fmats.2020.620000

\section{Hydrogen Diffusion and Its Effect on Hydrogen Embrittlement in DP Steels With Different Martensite Content}

\author{
Zhen Wang ${ }^{1,2}$, Jing Liu ${ }^{1,2 *}$, Feng Huang ${ }^{1,2}$, Yun-jie $\mathrm{Bi}^{1,2}$ and Shi-qi Zhang ${ }^{1,2}$ \\ ${ }^{1}$ The State Key Laboratory of Refractories and Metallurgy, Wuhan University of Science and Technology, Wuhan, China, ${ }^{2}$ Hubei \\ Engineering Technology Research Center of Marine Materials and Service Safety, Wuhan University of Science and Technology, \\ Wuhan, China
}

The hydrogen diffusion behavior and hydrogen embrittlement susceptibility of dual phase (DP) steels with different martensite content were investigated using the slow strain-rate tensile test and hydrogen permeation measurement. Results showed that a logarithmic relationship was established between the hydrogen embrittlement index $\left(/_{\mathrm{HE}}\right)$ and the effective hydrogen diffusion coefficient $\left(D_{\text {eff }}\right)$. When the martensite content is low, ferrite/ martensite interface behaves as the main trap that captures the hydrogen atoms. Also, when the $D_{\text {eff }}$ decreases, $I_{\mathrm{HE}}$ increases with increasing martensite content. However, when the martensite content reaches approximately $68.3 \%$, the martensite grains start to form a continuous network, $D_{\text {eff }}$ reaches a plateau and $I_{H E}$ continues to increase. This is mainly related to the reduction of carbon content in martensite and the length of ferrite/martensite interface, which promotes the diffusion of hydrogen atoms in martensite and the aggregation of hydrogen atoms at the ferrite/martensite interface. Finally, a model describing the mechanism of microstructure-driven hydrogen diffusion with different martensite distribution was established.

\footnotetext{
Keywords: dual phase steels, hydrogen embrittlement, hydrogen diffusion, martensite content, slow strain rate tensile test
}

\section{INTRODUCTION}

As the automobile industry has developed rapidly, lightweight automobile components have become important means for conserving energy and reducing emissions (Li et al., 2003). Dual phase (DP) steel composed of ferrite and martensite has become a favored material for the manufacturing of automobile structural parts, reinforcement parts and anti-collision parts due to the inherent high strength, sound formability and weldability (Sirinakorn et al., 2014). DP steels of different strength grades can be obtained by controlling the martensite content (Khan et al., 2008). However, the presence of hydrogen permeation in materials during processing, pickling, welding and service is prone to the risk of hydrogen embrittlement (Robertson et al., 2015). Furthermore, the magnitude of the hydrogen influence increased with increasing strength, severely limiting the development of high strength DP steels (Loidl et al., 2011).

Using the in-situ tensile test and SEM observation, Koyama (Koyama et al., 2014) found that hydrogen atoms gathering on the martensite promoted the cleavage fracture of martensite phase. Under static hydrogen charging, the interface of ferrite/martensite and martensite lath would become wider with increasing hydrogen charging current density, resulting in microcracks (Sun et al., 1989). Therefore, hydrogen embrittlement susceptibility of DP steel is related to the martensite. 
TABLE 1 | Chemical composition of the experimental steel (wt \%).

\begin{tabular}{lcccccccc}
\hline C & Si & Mn & Cr & Al & S & $\mathbf{P}$ & Mo & Fe \\
\hline 0.210 & 0.240 & 1.280 & 0.300 & 0.040 & 0.011 & 0.007 & 0.001 & Balance
\end{tabular}

Previous studies have shown that hydrogen embrittlement is generally caused by local hydrogen enrichment trapped at dislocations, grain boundaries etc. and a high density of hydrogen traps would reduce the diffusion coefficient of hydrogen (Hadžipašić et al., 2011a; Loidl et al., 2011; Robertson et al., 2015). Steels containing martensite phases have higher capacities for capturing hydrogen atoms than those containing other types of phases, such as ferrite, pearlite, etc., and therefore steels with relatively low hydrogen diffusion coefficients will be more susceptible to hydrogen embrittlement (Hadžipašić et al., 2011a; Hadžipašić et al., 2011b; Hui et al., 2019). Meanwhile, with the increase of the martensite content, the concentration of hydrogen traps increased, and the effective hydrogen diffusion coefficient decreased (Liu et al., 2016a; Liu et al., 2018). As a result, compared with the DP980 steel, DP1200 steel is more sensitive to hydrogen embrittlement and the tensile elongation decreased from 9 to $5 \%$ after hydrogen charging (Loidl et al., 2011).

However, the increasing of martensite content is often coupled with a change in distribution morphology. Davies (Davies, 1981; Davies, 1983) found that hydrogen embrittlement susceptibility of DP steel did not increase linearly with increasing the martensite content from 0 to $45 \%$. When the martensite content is lower than $30 \%$, hydrogen embrittlement susceptibility increases with martensite content increasing. However, when the martensite content increases to $30 \%$, the martensite phase starts to distribute continuously along the grain boundary and hydrogen embrittlement susceptibility reaches a stable value. But up till date, how martensite content and morphology distribution affects hydrogen diffusion is still not investigated.

Therefore, in this study, we investigated the hydrogen embrittlement behavior of DP steels using slow-strain rate tensile tests. The electrochemical permeation technique was used to investigate hydrogen diffusion behavior, particularly focusing on the influence of martensite distribution on hydrogen diffusion. A mathematical relationship was established between the effective hydrogen diffusion coefficient and the hydrogen embrittlement index to evaluate the hydrogen embrittlement susceptibility from the perspective of hydrogen diffusion.

\section{EXPERIMENTAL SECTION}

\section{Material Characterization}

Cold rolled steel sheets with an as-received thickness of $1.4 \mathrm{~mm}$ were used in this study. The chemical composition of the steel is presented in Table 1. Samples of $200 \mathrm{~mm} \times 50 \mathrm{~mm}$ cut along the rolling direction were annealed in a tube vacuum furnace for $30 \mathrm{~min}$ and quenched in water. Based on thermo-calc software $\left(\mathrm{A}_{\mathrm{cl}}=780^{\circ} \mathrm{C}, \mathrm{A}_{\mathrm{c} 3}\right.$ $=870^{\circ} \mathrm{C}$ ), the annealing temperatures of $780,810,840$, and $870^{\circ} \mathrm{C}$ were selected to obtain the desired quantity of martensite. A microstructural study of the samples was conducted using a high-

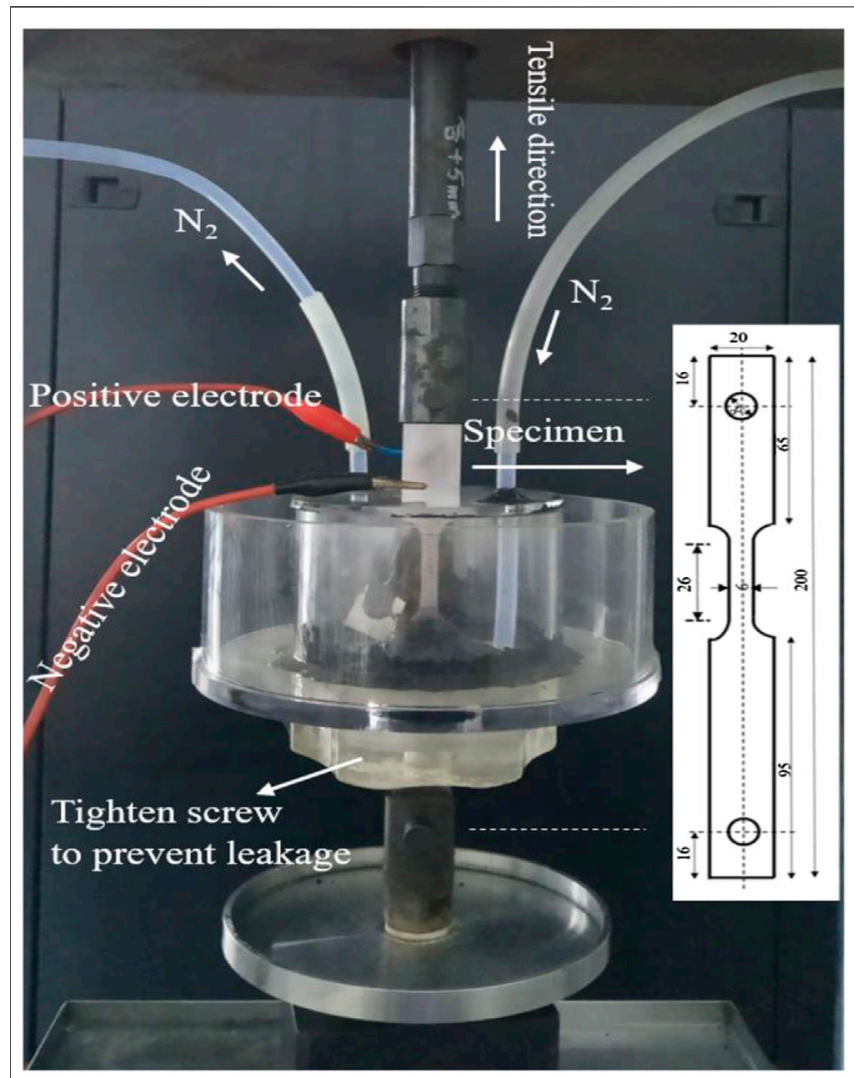

FIGURE 1 | Experimental set-up for tensile test under in situ electrochemical hydrogen charging, the dimensions of specimen are in $\mathrm{mm}$.

resolution SEM (FEI Nova 400 Nano). Combined with Image Pro Plus software, martensite content, average grain size and length of the ferrite/martensite interface were counted by ten SEM photographs in $5,000 \times$ magnification. The detailed microstructure of the martensite was analyzed by JEM - 2101FXIITEM.

\section{Testing of Hydrogen Embrittlement Susceptibility}

Hydrogen embrittlement susceptibility measurements were carried out on pre-polished tensile samples $(26 \mathrm{~mm} \times 6 \mathrm{~mm} \times 1.4 \mathrm{~mm})$ using a slow strain rate tensile test machine (WDML-3) under in situ electrochemical $\mathrm{H}$-charging. The device and specimen shape were shown in Figure 1. The same method was also described in literature (Yuan et al., 2018). The strain rate was selected as $1 \times 10^{-6} \mathrm{~s}^{-1}$ to facilitate keeping the diffusion of hydrogen atoms in step with the dislocation movement, thereby resulting in hydrogen embrittlement (Kumamoto et al., 2019). Both the hydrogen-charged and uncharged specimens were subjected to tensile test, with the former group referred as "H-charged" group, and the latter group referred as "air" group. For H-charged group, hydrogen charging tests were carried out in an aqueous solution of $0.5 \mathrm{~mol} / \mathrm{L} \mathrm{H}_{2} \mathrm{SO}_{4}$ and $1 \mathrm{~g} / \mathrm{L}$ $\mathrm{Na}_{4} \mathrm{P}_{2} \mathrm{O}_{7}$ with a current density of $10 \mathrm{~mA} / \mathrm{cm}^{2}$. The solution was purged with $\mathrm{N}_{2}$ for $2 \mathrm{~h}$ prior to testing to remove any oxygen and continuously purged with $\mathrm{N}_{2}$ throughout the experiment. 

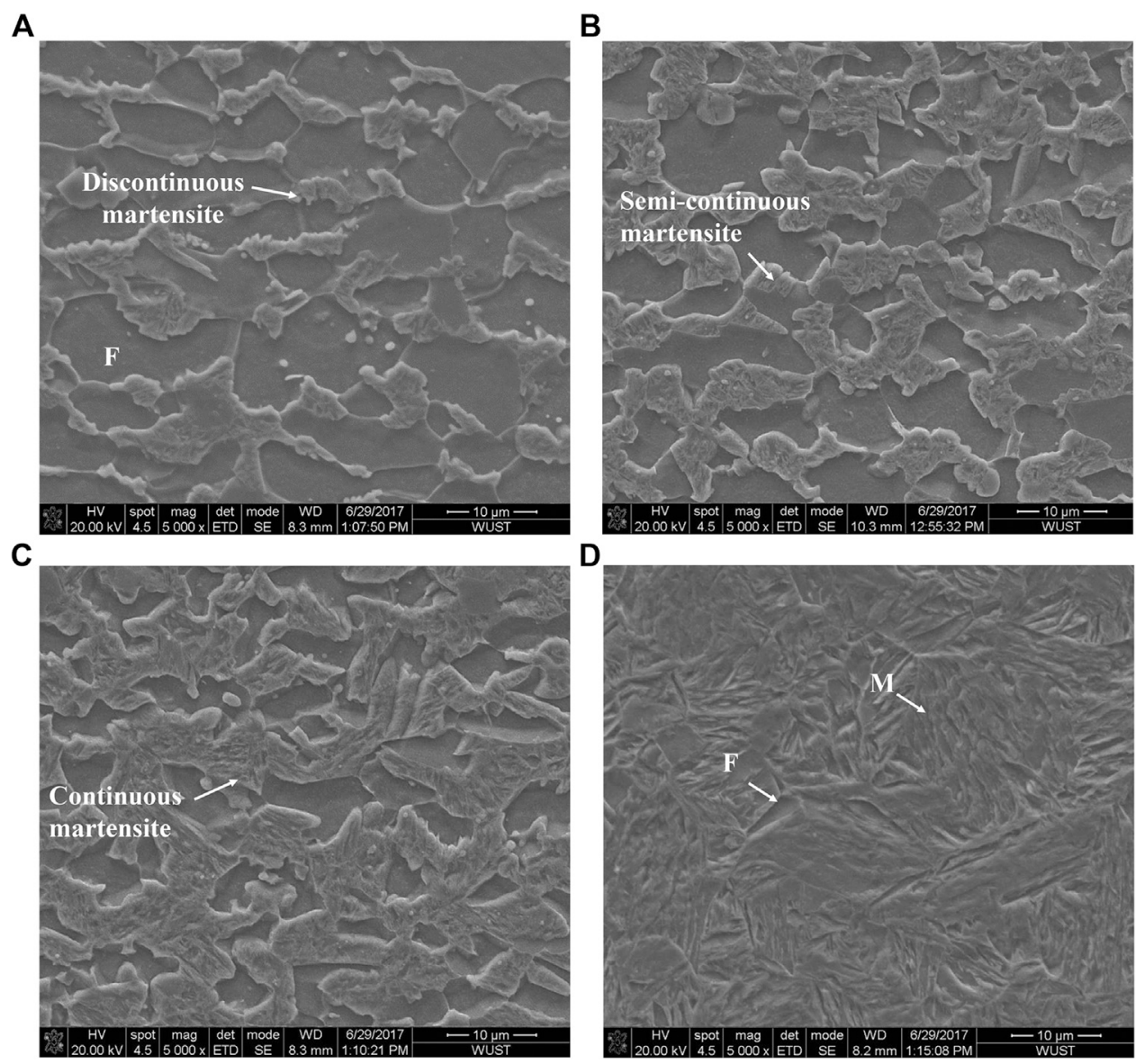

FIGURE 2 | SEM images of DP steels after annealing at (A) $780^{\circ} \mathrm{C}$; (B) $810^{\circ} \mathrm{C}$; (C) $840^{\circ} \mathrm{C}$; and (D) $870^{\circ} \mathrm{C}$.

\section{Hydrogen Permeation Test}

The hydrogen diffusion behavior of the DP steels was investigated using the hydrogen permeation test conducted in double electrolyte-cells (Chen et al., 2019). The dimensions of the samples used were $20 \mathrm{~mm} \times 30 \mathrm{~mm} \times$ $1.4 \mathrm{~mm}$. Both sides of the specimens were polished to eliminate flux-limiting surface impedances and ensure the reliability of the measurement of the hydrogen oxidation current. A circular area of $1 \mathrm{~cm}^{2}$ was exposed to the electrolytic cells. The receiving cell was filled with $300 \mathrm{ml}$ of $0.1 \mathrm{~mol} / \mathrm{L} \mathrm{NaOH}$ before applying a constant positive voltage of $250 \mathrm{mV}$ to the steel membrane. When the anode current fell below $10^{-8} \mathrm{~A}, 300 \mathrm{ml}$ of $0.5 \mathrm{~mol} / \mathrm{L} \mathrm{H}_{2} \mathrm{SO}_{4}$ and $1 \mathrm{~g} / \mathrm{L} \mathrm{Na}_{4} \mathrm{P}_{2} \mathrm{O}_{7}$ were added to the hydrogen charging cell and a charging current of $10 \mathrm{~mA} / \mathrm{cm}^{2}$ was maintained. When the permeation rate achieved a steady-state level, the successive decay curve was measured after stopping the current and discharging the acid solution, until the anode current dropped below $10^{-8} \mathrm{~A}$. The solution used was deoxidized in advance and the $\mathrm{N}_{2}$ continued to pass through the solution during the experiment. All experiments were performed at room temperature. To ensure reliability of the experimental data, each test was repeated at least three times.

\section{Hydrogen Microprint Test}

Immediately after hydrogen charging, the charging sides of original samples without tensile were lightly polished and etched with $2 \%$ nital. Hydrogen microprinting was achieved by immersing the samples in a solution of a $10 \mathrm{~g} \mathrm{AgBr}$ emulsion in $20 \mathrm{ml}$ of $1.4 \mathrm{~mol} / \mathrm{L} \mathrm{NaNO}_{2}$ at $45^{\circ} \mathrm{C}$ for $30 \mathrm{~min}$ in the darkroom. Hydrogen atoms were replaced by $\mathrm{Ag}$ on the specimen surface from the solution via a redox reaction (Ohmisawa et al., 2003). The specimens were rinsed in a 5\% $\mathrm{NaNO}_{2}$ aqueous solution. The microstructure was analyzed to determine the distribution of silver particles on SEM.

\section{RESULTS}

\section{Microstructure Characterization}

Figure 2 showed that the microstructure of annealed samples consisted of both ferrite $(\mathrm{F})$ and martensite $(\mathrm{M})$. The martensite was small and discontinuous when annealed at $780^{\circ} \mathrm{C}$. However, with the increase of annealing temperature, the content and the size of martensite increased. Martensite grains were gradually in a continuous manner over the ferrite grain boundaries. Distribution of martensite changed from semi-continuous style 
TABLE 2 | Content of martensite, average size of ferrite (F), average size of martensite $(\mathrm{M})$ and length of ferrite/martensite $(\mathrm{F} / \mathrm{M})$ in DP steels.

\begin{tabular}{lcccc} 
Temperature $\left({ }^{\circ} \mathbf{C}\right)$ & $\mathbf{7 8 0}$ & $\mathbf{8 1 0}$ & $\mathbf{8 4 0}$ & $\mathbf{8 7 0}$ \\
\hline Content $(\%)$ & 18.5 & 46.7 & 68.3 & 96.3 \\
Size of $\mathrm{M}(\mu \mathrm{m})$ & 2.63 & 7.14 & 10.52 & 12.63 \\
Size of $\mathrm{F}(\mu \mathrm{m})$ & 9.21 & 8.57 & 3.94 & 1.98 \\
Length of $\mathrm{F} / \mathrm{M}\left(10^{-2} \mu \mathrm{m} / \mu^{2}\right)$ & 6.59 & 17.90 & 9.87 & 4.65
\end{tabular}

to a continuous network. The length of the ferrite/martensite (F/ $\mathrm{M})$ interface initially increased and subsequently decreased, as showing in Table 2. It is mainly because the length of the F/M interface depended largely on the size of dispersed martensite when the martensite distribution is discontinuous, while it depended on the ferrite size when martensite was distributed in a continuous network. Figure 3 revealed a high density of dislocations in the ferrite region around the F/M interface. In
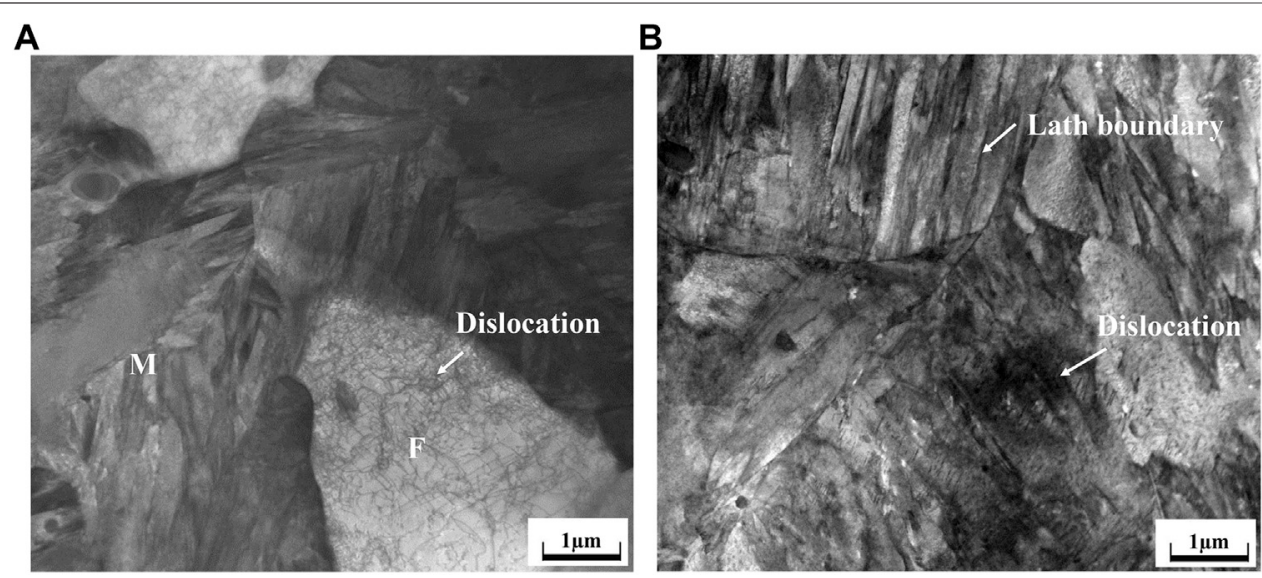

FIGURE 3 |TEM images of DP steel with 68.3\% martensite content: (A) Dislocations in the ferrite region around the F/M boundary; and (B) dislocations and lath boundaries in the martensite.
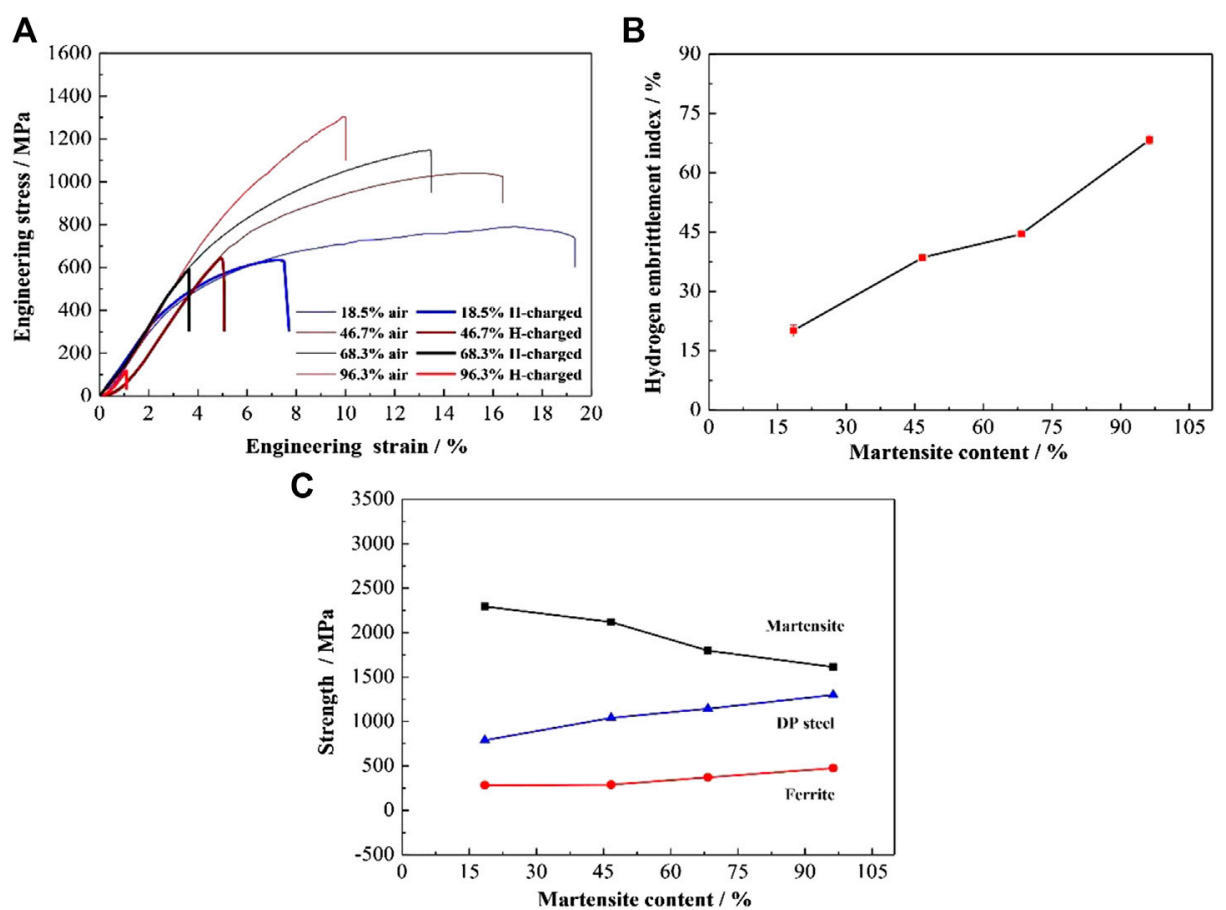

FIGURE 4 | (A) Stress-strain curves; (B) hydrogen embrittlement susceptibility; and (C) strength of ferrite and martensite of DP samples with different martensite content. 

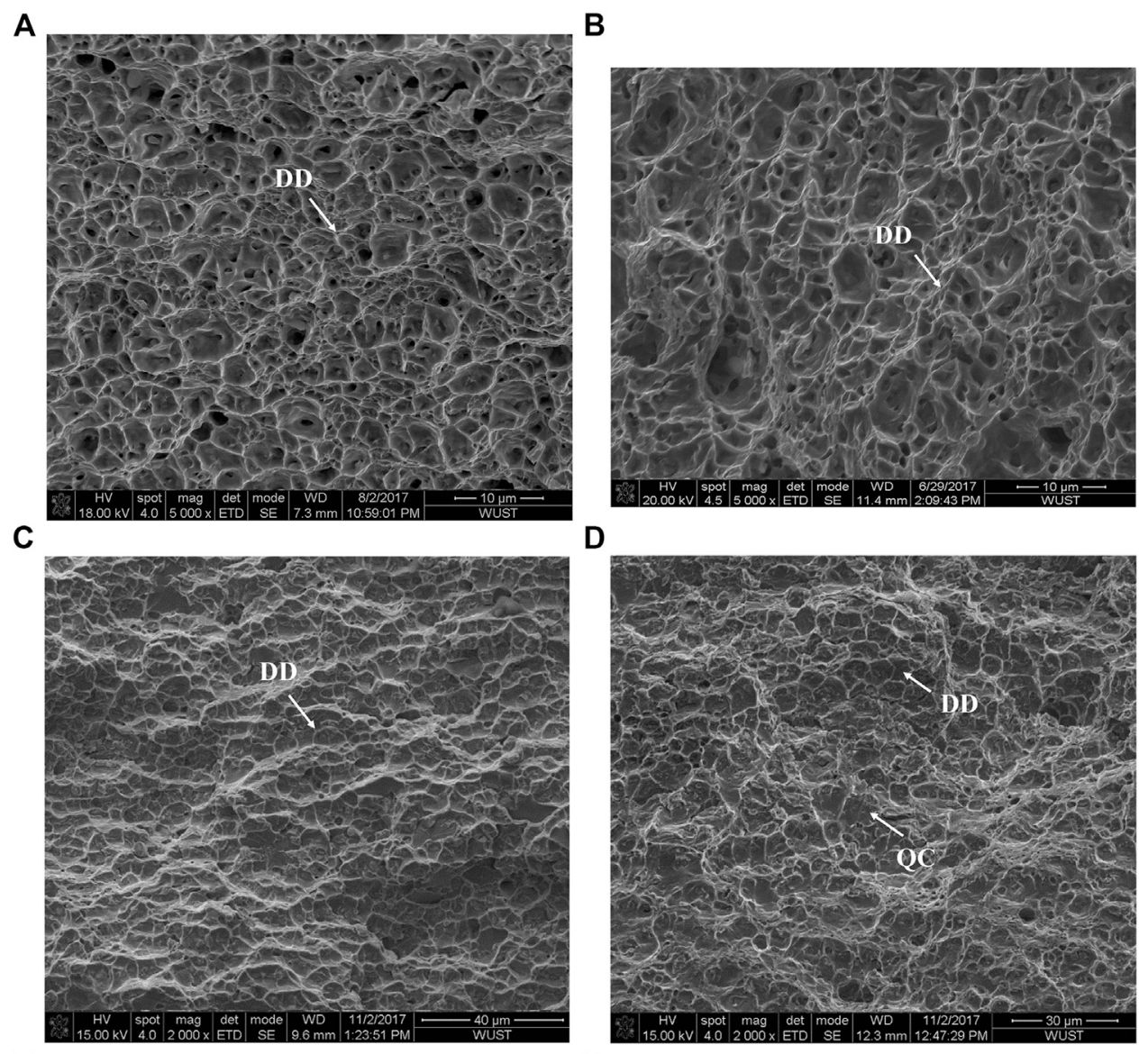

E
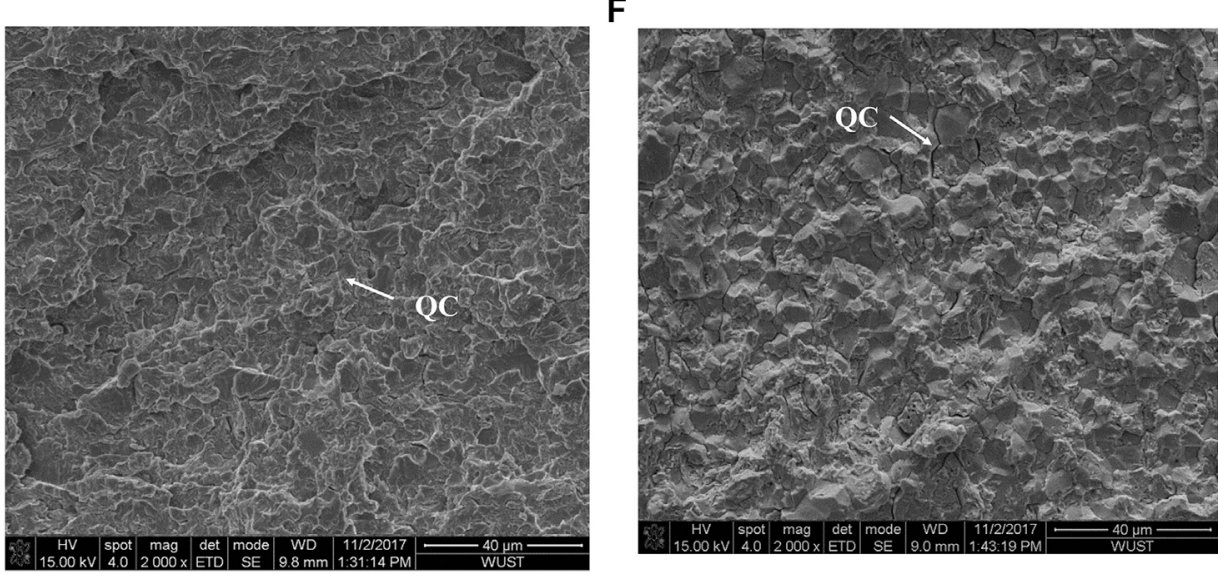

FIGURE 5 | Fracture surface morphologies of DP steels with different martensite content: (A) 18.5\% with non-charged; (B) $96.3 \%$ with non-charged; (C) $18.5 \%$ with $\mathrm{H}$-charged; (D) $46.7 \%$ with $\mathrm{H}$-charged; (E) $68.3 \%$ with $\mathrm{H}$-charged and (F) $96.3 \%$ with $\mathrm{H}$-charged.

addition, a high density of lath boundaries and dislocations were observed within the martensite.

\section{Hydrogen Embrittlement Susceptibility}

When the specimen was stretched slowly in an acidic solution, the plastic index decreased, causing embrittlement of the material, known as hydrogen-induced plastic loss. The hydrogen embrittlement index $\left(I_{\mathrm{HE}}\right)$ is defined as (Loidl et al., 2011):

$$
I_{\mathrm{HE}}=\left(\delta_{0}-\delta_{\mathrm{H}}\right) / \delta_{0} \times 100 \%
$$

where $\delta_{0}$ is the elongation of specimens in air and $\delta_{\mathrm{H}}$ is the elongation of specimens with hydrogen charging. $I_{\mathrm{HE}}$ can vary from $0 \%$ with no ductility loss, to $100 \%$ with total loss in ductility.

The tensile strength and total elongation of the samples decreased significantly due to hydrogen charging (Figure 4A). An increase in annealing temperature resulted in an increase in martensite content 


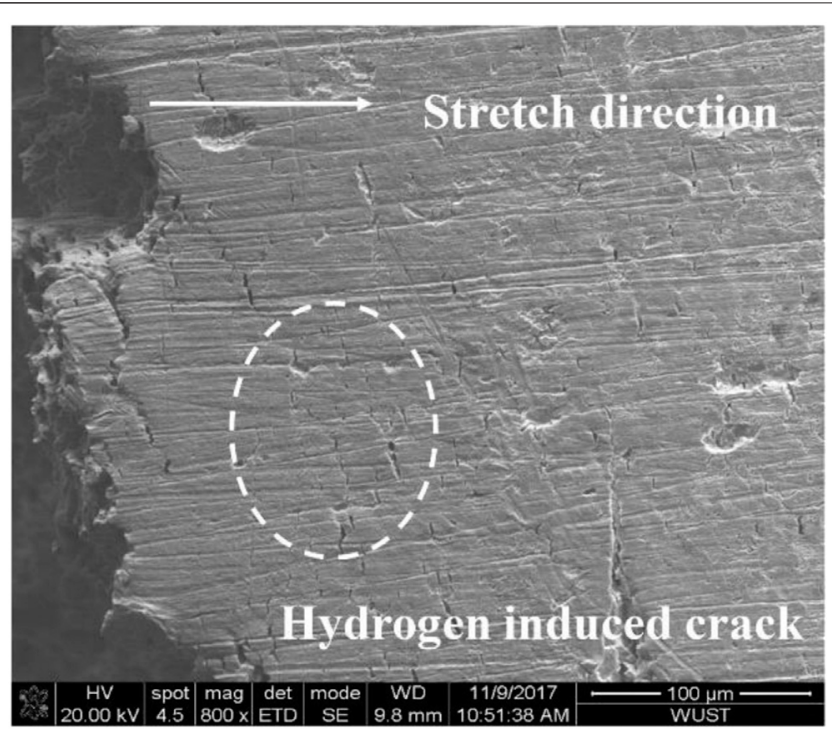

FIGURE 6 | Lateral fracture surface morphology of DP steel with martensite content in $18.5 \%$.

and consequently the hydrogen embrittlement index (Figure 4B). Figure 4C shows the variation of strength in ferrite and martensite. With the increase of martensite content, the strength of ferrite increases while the martensite's decreases. The strength of ferrite can be calculated by the formula (Jahanara et al., 2019), $\sigma_{b}^{F}=\sigma_{i}+K_{y} d^{-1 / 2}+69$, where $\sigma_{i}$ is lattice friction ( $\left.49 \mathrm{MPa}\right), K_{y}$ is constant $\left(500 \mathrm{MPa} \mu \mathrm{m}^{1 / 2}\right)$, and $d$ is the grain size of ferrite (see Table 2). The martensite's strength can be achieved by the formula (Xia and Zhou, 2000), $\sigma_{b}^{M}=541+2289\left(C_{m}\right)^{1 / 2}, C_{m}$ is the carbon content in the martensite, which can be obtained by thermocalc software. The values are $0.589,0.475,0.301$, and $0.220 \%$ respectively corresponding to the martensite content with 18.5 , 46.7, 68.3 , and $96.3 \%$.

Figure 5 shows the fracture surface morphologies of the tensile steels. The fracture surface morphologies of the non-charged samples present ductile fracture features (Figures 5A,B). After hydrogen charging, the proportion of brittle fracture characteristics increases gradually with increasing martensite content. Uniform ductile dimples (DD) appear on the sample with low martensite content $18.5 \%$ (Figure 5C), the dimples (DD) become shallower, and some quasi-cleavage (QC) fracture features appear with increasing martensite content (Figure 5D). When the martensite content reaches over $68.3 \%$, the fracture completely exhibits brittle characteristics of a quasi-cleavage (QC) fracture (Figure 5E) and intergranular fracture (Figure 5F). Combined with microstructural observation in Figure 2, it was found that when the martensite content is low and the martensite are distributed, the steel is mainly characterized by ductile fracture. As the martensite content increased, the martensite became a continuous network and the fracture surface presents brittle features.

Lateral fracture surface morphology examination showed several secondary hydrogen-induced cracks, which formed on the surface of tensile samples with low martensite content, are perpendicular to the direction of tensile stress and adjacent to the main fracture (Figure 6). When the martensite content reached $68.3 \%$, brittle fractures occurred directly in the hydrogen charging solution without any cracks on the side of the fracture. Detailed SEM observation revealed that the most secondary hydrogeninduced cracks was initiated at the $\mathrm{F} / \mathrm{M}$ interface and propagated toward the martensite, whereas the ferrite acted as crack propagation barriers (Figure 7A). As the martensite content increased, the grain size of martensite increased, and the hydrogen-induced cracks started to propagate continuously throughout martensite grains (Figure 7B). Hydrogen microprinting confirmed that most of the silver particles clustered at the ferrite/martensite interfaces (Figure 8), indicating the aggregation of hydrogen atoms at the interface.

\section{Hydrogen Permeation Test}

Hydrogen diffusion in DP steel is strongly influenced by the presence of martensite. As the martensite content increased, both the permeation time and desorption time increased, while the steady state current decreased (Figure 9).

Permeation experiments allow the determination of hydrogen permeation parameters via the following methods (Liu et al., 2016b). The hydrogen flux through the sample was measured by the steady state hydrogen current density, $I_{\infty}$, which is converted into hydrogen permeation flux, $J_{\infty}$ by Eq. 2 .

$$
J_{\infty}=\frac{I_{\infty}}{F A}
$$

where $A$ is the sample area and $F=96,485 \mathrm{C} / \mathrm{mol}$ is the Faraday constant. In this study, $A=1 \mathrm{~cm}^{2}$. The effective hydrogen diffusivity, $D_{\text {eff, }}$ can be calculated by Eq. 3 .

$$
D_{\text {eff }}=\frac{L^{2}}{6 t_{0.63}}
$$

where $\mathrm{L}$ is the thickness of the sample and $t_{0.63}$ is the corresponding time for $0.63 I_{\infty}$, as shown by the arrows in Figure 9A. In this work, $L$ is $1.4 \mathrm{~cm}$. The hydrogen concentration at the charging side, $C_{0}$, can be calculated by Eq. 4.

$$
C_{0}=\frac{J_{\infty} L}{D_{\text {eff }}}
$$

The hydrogen trapping density can be estimated by Eq. 5 .

$$
N_{T}=\frac{C_{0}}{3}\left(\frac{D_{L}}{D_{\text {eff }}}-1\right)
$$

$D_{L}$ is the lattice diffusion coefficient of hydrogen, which can be estimated by fitting the permeation Eq. 6 to the experimental permeation during the 1-0.8 desorption step.

$$
\frac{i_{p}-i_{p}^{\infty}}{i_{p}^{0}-i_{p}^{\infty}}=1-\frac{2 L}{\sqrt{\pi D t}} \sum_{n=0}^{\infty} \exp \left(-\frac{(2 n+1)^{2} L^{2}}{4 D t}\right)
$$

where $i_{p}^{0}$ is the initial steady-state permeation rate at time $\mathrm{t}=0$, and $i_{p}^{\infty}$ is the steady-state permeation. The accuracy of the fitting curve that can be met with $\mathrm{n}$ is $0,1,2,3,4$. 

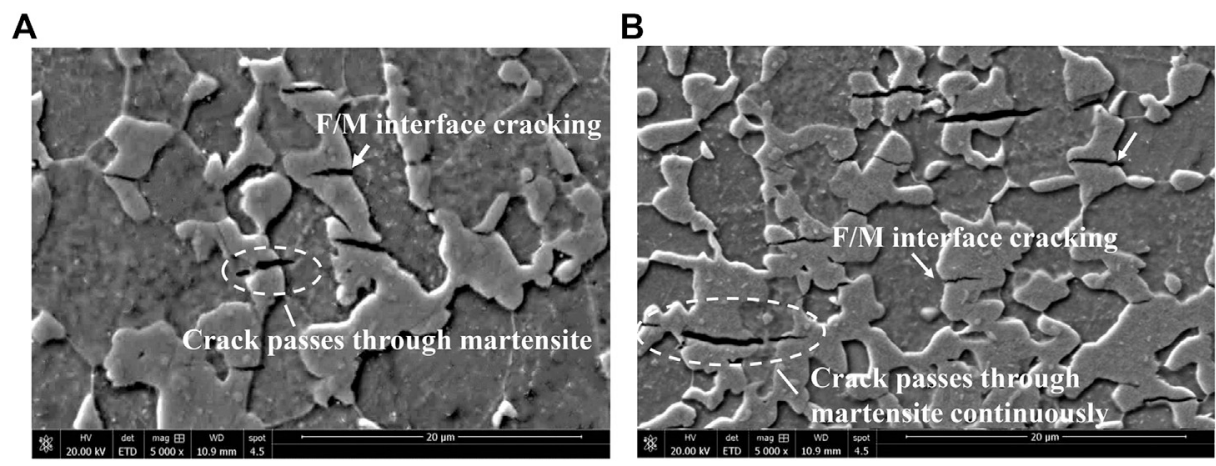

FIGURE 7 | Hydrogen-induced cracks of DP steels with different martensite content: (A) 18.5\%; and (B) $46.7 \%$.
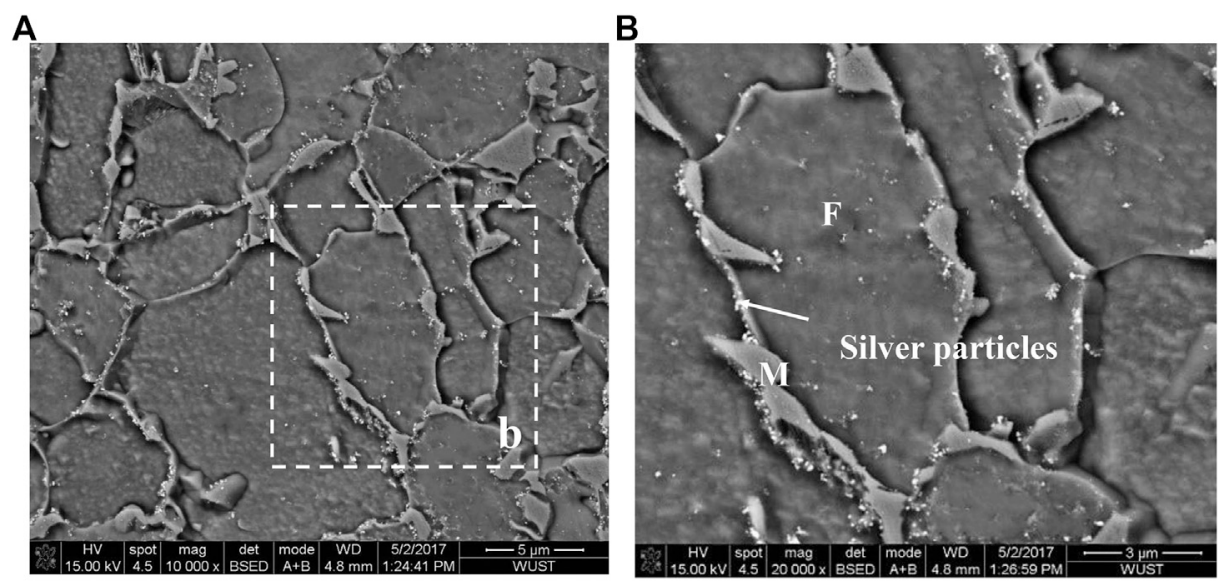

FIGURE 8 | (A) Hydrogen microprints showing hydrogen concentration at the F/M interface in a sample with $18.5 \%$ marteniste content; and (B) the corresponding enlarged image.
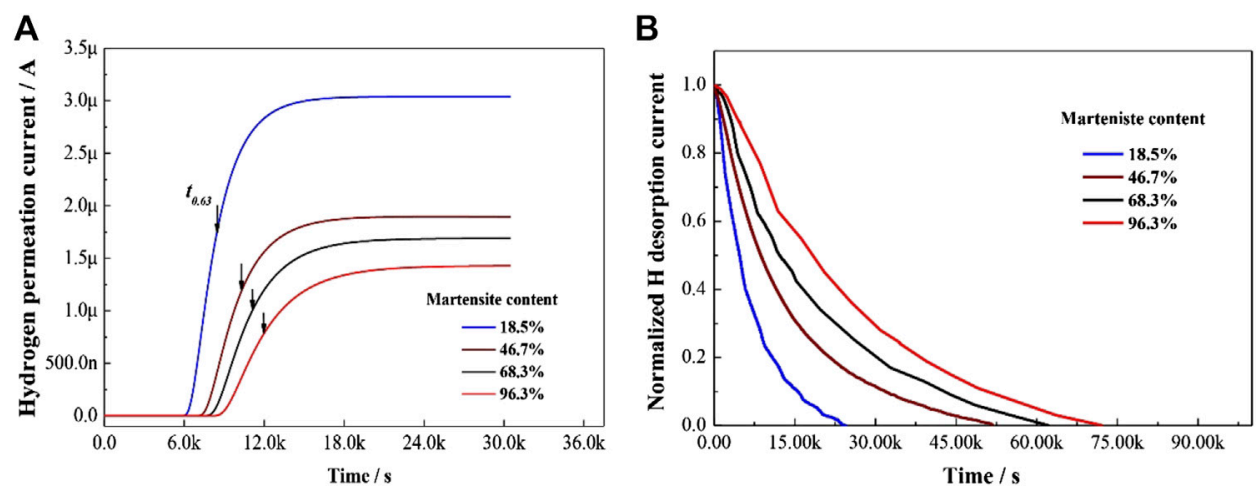

FIGURE 9| Hydrogen permeation curves of DP samples: (A) Hydrogen permeation during charging step; and (B) hydrogen permeation during desorption step.

Table 3 shows the hydrogen permeability parameters in DP steels. As the martensite content increased, the hydrogen trapping density $N_{T}$ increased, and the effective hydrogen diffusion coefficient $D_{\text {eff }}$ and the hydrogen permeation flux $J_{\infty}$ decreased.

Figure 10 shows the relationship between martensite content and the calculated hydrogen diffusion coefficient. In order to ensure the accuracy of linear fitting, an DP steel with smaller martensite content $(<18.5 \%)$ is needed. As it was hard to obtain a sample with martensite content below $18.5 \%$ using the current steel with 2.0 wt \% carbon content, DP steel with 1.0 wt \% carbon content and the similar content of other elements were subjected to heat treatment. After annealing in the two-phase zone, $6.49 \%$ 
TABLE 3 | Hydrogen permeation parameters of DP steels.

\begin{tabular}{|c|c|c|c|c|}
\hline Martensite content, $\%$ & $\begin{array}{c}J_{\infty}, \mathrm{mol} \cdot \mathrm{cm}^{-2} \\
\mathrm{~s}^{-1}\end{array}$ & $t_{0.63}, \mathrm{~s}$ & $\begin{array}{c}D_{\text {eff }}, \mathrm{cm}^{2} . \\
\mathrm{s}^{-1}\end{array}$ & $N_{T}, \mathrm{~mol} / \mathrm{cm}^{3}$ \\
\hline 18.5 & $3.16 \times 10^{-11}$ & 8,757 & $3.73 \times 10^{-7}$ & $2.13 \times 10^{-6}$ \\
\hline 46.7 & $1.96 \times 10^{-11}$ & 11,264 & $2.90 \times 10^{-7}$ & $2.30 \times 10^{-6}$ \\
\hline 68.3 & $1.74 \times 10^{-11}$ & 11,666 & $2.80 \times 10^{-7}$ & $2.61 \times 10^{-6}$ \\
\hline 96.3 & $1.47 \times 10^{-11}$ & 11,793 & $2.77 \times 10^{-7}$ & $2.77 \times 10^{-6}$ \\
\hline
\end{tabular}

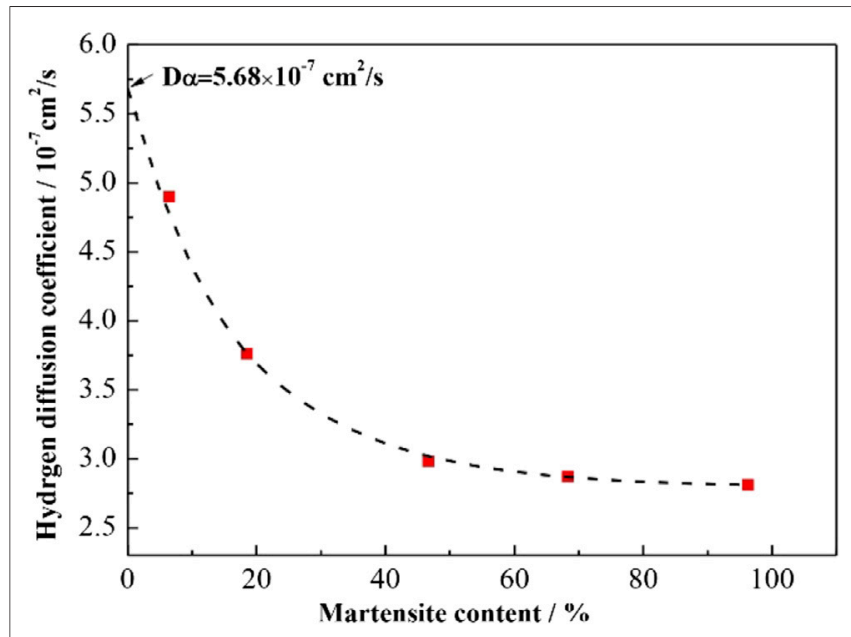

FIGURE 10 | The correlation of the hydrogen diffusion coefficient as a function of martensite content in DP steel.

martensite content was obtained. The hydrogen diffusion coefficient in this sample was $4.90 \times 10^{-7} \mathrm{~cm}^{2} / \mathrm{s}$. Due to the very low martensite content, the hydrogen atoms primarily diffused along the ferrite (Owczarek and Zakroczymski, 2000). As most of the carbon atoms were presented in the martensite, the effect resulted by the decrease of carbon content from 2 to 1 wt \% on the diffusion coefficient of steel could be ignored, which makes the linear fitting reliable. As the martensite content increased, the hydrogen diffusion coefficient decreased rapidly before leveling off at approximately $68.3 \%$ or higher martensite content. By extrapolating the curve to $0 \%$ martensite, the effective hydrogen diffusion coefficient $\left(D_{\alpha}\right)$ in the ferrite phase was about $5.68 \times 10^{-7} \mathrm{~cm}^{2} / \mathrm{s}$.

According to the previous hydrogen diffusion model (Owczarek and Zakroczymski, 2000), the change in the desorption rate of hydrogen atoms in martensite $i_{m}$ with time $t$ can satisfythe Eq. 7:

$$
\begin{aligned}
i_{m}= & 4 \pi D_{m} C_{m, 0}^{*}\left\{\exp \left[-\frac{D_{m}(2.404)^{2} t}{R^{2}}\right]+\exp \left[-\frac{D_{m}(5.520)^{2} t}{R^{2}}\right]\right. \\
& \left.+\exp \left[-\frac{D_{m}(8.654)^{2} t}{R^{2}}\right]+\ldots\right\}
\end{aligned}
$$

In the formula, $C_{m, 0}^{*}$ is the initial concentration of hydrogen atoms in the martensite at the beginning of desorption; $D_{m}$ is the effective hydrogen diffusion coefficient in the martensite; and $\mathrm{R}$ is the average equivalent diameter of the martensite. When the desorption time $t \rightarrow \infty$, only the first term in Eq. 7 can make the equation hold, as shown in Eq. 8:

$$
i_{m}=4 \pi D_{m} C_{m, 0}^{*}\left\{\exp \left[-\frac{D_{m}(2.404)^{2} t}{R^{2}}\right]\right\}
$$

Using the logarithm of Eq. 8, a linear correlation with time, $t$ is revealed:

$$
\log i_{m}=\log \left(4 \pi D_{m} C_{m, 0}^{*}\right)-\frac{D_{m}(2.404)^{2} t}{R^{2}}
$$

Therefore, after a certain time, the logarithm of the desorption rate should be a linear function of time with a slope dependent only on $D_{m}$ and R.

To establish the hydrogen desorption current curve in the martensite, $i_{m}$, we first calculated the hydrogen desorption current in the pure ferrite, $i_{\alpha}$ by substituting the ferrite's diffusion coefficient in Eq. 6. The hydrogen desorption curves in the martensite can be calculated by subtracting the desorption curve of the ferrite from the measured desorption curve of DP steel, i.e., $i_{m}=i-i_{\alpha}$, as shown in Figure 11A. Using the method, the hydrogen desorption curves in the martensite can be obtained, as showing in Figure 11B. Combining Eq. 9, the effective hydrogen diffusion coefficient $D_{m}$ of hydrogen atoms can be obtained.

The results are largely consistent with the hydrogen diffusion coefficient in pure martensite steel (Frappart et al., 2012). The effective hydrogen diffusion coefficient in martensite $\left(D_{m}\right)$ increased with the martensite content (Figure 12A), possibly due to a decrease in the carbon concentration of the martensite. Carbon content in martensite was obtained by thermo-calc software against intercritical annealing temperature. As the intercritical annealing temperature increased, the proportion of carbon in the martensite decreased (Figure 12B).

\section{DISCUSSION}

\section{Effect of Martensite Content and Distribution on Hydrogen Diffusion of DP Steels}

Previous studies have shown that the decrease in hydrogen diffusion coefficient of DP steel is correlated to martensite, which contains a high density of dislocations and other defects to capture hydrogen atoms (Sun et al., 1989; Hadžipašić et al., 2011a; Hadžipašić et al., 2011b; Koyama et al., 2014; Liu et al., 2016a; Liu et al., 2018; Hui et al., 2019). It is logical to deduce that the hydrogen diffusion coefficients decrease as martensite content increases. However, Figure 10 showed that once the martensite content reached approximately $68.3 \%$, the hydrogen diffusion coefficient started to level off. Therefore, the hydrogen diffusion is strongly influenced by not only the martensite content but also the distribution of the martensite phases. Depending on the characteristics of microstructure and hydrogen diffusion in DP steels, a model describing the mechanism of microstructure-driven hydrogen diffusion with different martensite distribution was established. 

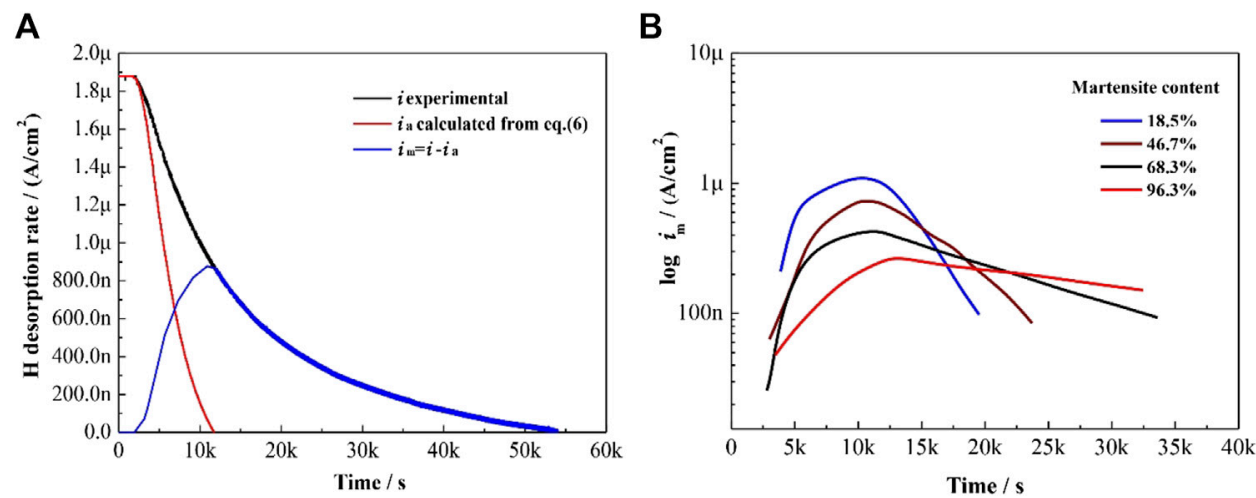

FIGURE 11 | (A) Desorption curves of ferritic and martensitic phases in DP steel with 46.7\% martensite content; and (B) calculated hydrogen desorption rate in the martensitic phase vs time.
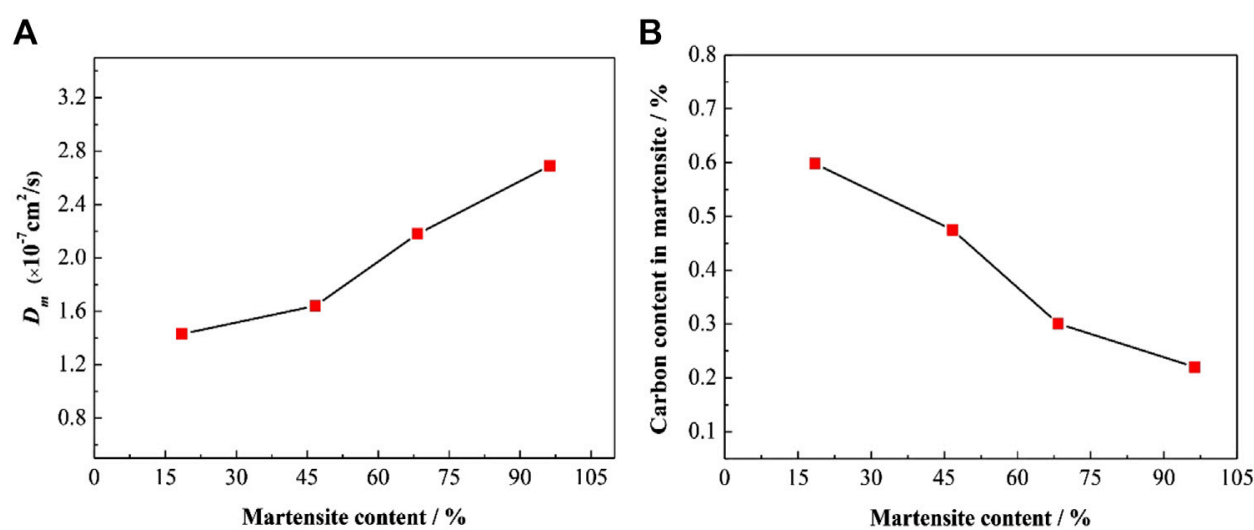

FIGURE 12 | (A) The hydrogen diffusion coefficient in martensite and (B) calculated carbon concentration vs the martensite content.
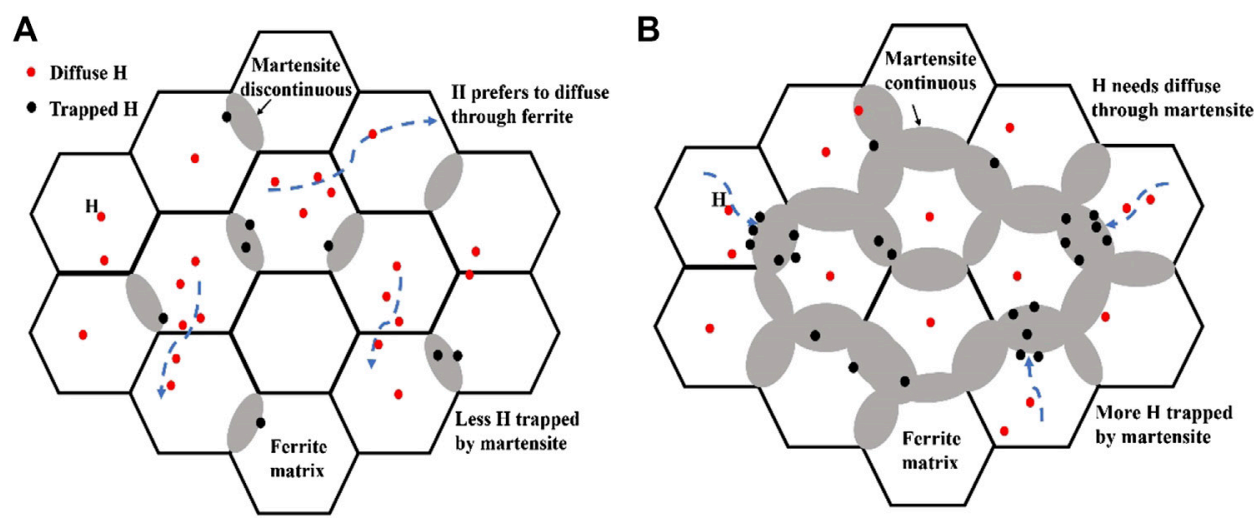

FIGURE 13|Schematic representation of the microstructure-driven hydrogen diffusion in DP steel: (A) distribution of martensite is discontinuous; (B) ditribution of martensite is continuous.

When the martensite content was relatively low, the martensite phases were in the form of small isolated islands (Figures 2A,B). Hydrogen atoms preferentially passed through the ferrite for its higher hydrogen diffusion coefficient than martensite. And they were unlikely to be accumulated, which could be reflected by a higher hydrogen diffusion flux and 
effective hydrogen diffusion coefficient in DP steel (Table 3). As the martensite content increased, the length of $\mathrm{F} / \mathrm{M}$ interface increased (Table 2), which acted as hydrogen traps. Hydrogen trapping effect at the interface could be observed directly through the hydrogen microprint (Figure 8). More martensite content resulted in higher hydrogen trapping effect, which presented an obvious decrease in both hydrogen diffusion flux and the effective hydrogen diffusion coefficient (Table 3).

However, when the martensite content increased to approximately $68.3 \%$, the distribution of martensite phases started to form a continuous network (Figures 2C,D). Hydrogen atoms have to diffuse across the martensite, and the fast diffusion channel of the hydrogen atoms along the ferrite disappears. (Figure 13B). Hydrogen atoms were captured by both the $\mathrm{F} / \mathrm{M}$ interface and martensite during diffusion. On one side, with the increasing of martensite content, the effective hydrogen diffusion coefficient in the steel continued to decrease due to a high density of dislocation and lath boundary in the martensite phase that acted as hydrogen traps, which is similar to the previous studies (Hui et al., 2019; Liu et al., 2016a; Kumamoto et al., 2019). On the opposite side, the carbon content in martensite decreased as the martensite content increased, which leading to the decreasing hydrogen trapping effect of carbon. Then the effective hydrogen diffusion coefficient increased as shown in Figure 12. The trapping effect between carbon and hydrogen atoms could refer to the literature (Geng et al., 2018). Therefore, the counterbalancing effect of the two opposite aspects leaded the hydrogen diffusion coefficients started leveling off.

\section{Effect of Martensite Content and Distribution on Hydrogen Embrittlement of DP Steels}

When subjected to thermomechanical treatment, there is stress concentrating around the $\mathrm{F} / \mathrm{M}$ interface due to the strain incompatibility between the soft ferrite and hard martensite, resulting in high density of dislocations around the interface (Figure 3A). During the process of hydrogen charging, hydrogen atoms could migrate with the movable dislocation and aggregated at the interface, then generated an attached stress and subsequently promoted the interface cracking (Zhang et al., 2003), thus the hydrogen-induced crack initiated at the $\mathrm{F} / \mathrm{M}$ interface and passed though the martensite (Figure 7).

When the martensite content was relatively low and the martensite phases were in the form of small isolated islands, the low concentration of hydrogen traps resulted in a low aggregation of hydrogen atoms. Thus, the additional stress generated by the hydrogen atom is low. Additionally, the soft ferrite could absorb parts of the plastic deformation energy during tension and effectively prevented the expansion of the crack (Figure 7A). Therefore, the hydrogen embrittlement index was low, and the tensile fracture surface presented the clear characteristics of the ductile fracture when martensite content was $18.5 \%$ (Figure 6A). With the increase of martensite content, the concentration of hydrogen traps increased and trapped more hydrogen atoms, which led to an increased additional hydrogeninduced stress at the interface of F/M. Additionally, with the decrease of ferrite size, the ferrite's strength increased and the susceptibility of ferrite to hydrogen embrittlement was also increased, which weakens the inhibition effect of ferrite on crack propagation. Therefore, the hydrogen embrittlement index of test steel increased from 20.28 to $38.89 \%$ and the dimples of tensile fractures became shallower, showing higher hydrogen embrittlement susceptibility.

However, when the martensite content increased to approximately $68.3 \%$, the distribution of martensite phases started to form a continuous network (Figures 2C,D). The concentration of hydrogen traps and the captured hydrogen atoms in steel were continued to increase. But the length F/M interface decreased with the decrease of ferrite size, and thus the additional hydrogen-induced stress at F/M interface would reach a critical fracture stress more easily. Additionally, the reduction of carbon content in martensite promoted the diffusion of hydrogen atoms in martensite. Therefore, the effective hydrogen coefficient reaches a plateau, but the hydrogen embrittlement sensitivity increased continuously with increasing martensite content and the tensile fracture showed obvious cleavage or brittle intergranular fracture morphology (Figures 5C,D). Therefore, the critical transition point of the influence of the martensite content on hydrogen embrittlement was the formation of a continuous network of martensitic phases. Previous studies (Davies, 1983) also showed that when the martensite content increased to $30 \%$ and formed a continuous network, the hydrogen embrittlement susceptibility of DP steel reached a stable value. This may be related to the distribution of the long trip martensite along the interface. And the length of F/M interface didn't significantly change when the martensite content exceeds $30 \%$. However, in this study, the morphology of martensite is block and the length of $\mathrm{F} / \mathrm{M}$ interface decreased significantly with the increasing martensite content when the distribution of martensite is continuous in DP steel, which results in a continuously increasing of hydrogen embrittlement susceptibility.

Additionally, with the increase of martensite content, the strength of ferrite increases while the martensite's decreases, which could improve the deformation compatibility between the two phases (Figure 4C). A better deformation compatibility results in a more uniformly distribution of strain during the tensile deformation and could reduce the occurrence of pores and microcracks at the interface of the ferrite/martensite. However, with the increase of martensite content, the total hydrogen concentration trapped by the steel increases (Table 3). More hydrogen atoms could aggregate in the defect sites (such as ferrite/martensite interfaces or inclusions) of steel, and thus promoting nucleation. Moreover, the martensite matrix is more susceptible to the hydrogen embrittlement and has lower crack resistance, hydrogen-induced cracks are easier to propagate in DP steel with higher martensite content (Figure 7B). In summary, the increasing martensite content played dual roles in the hydrogen embrittlement of DP steels, with the harmful role far outweighed the beneficial role, finally leading to the increased hydrogen embrittlement susceptibility. 

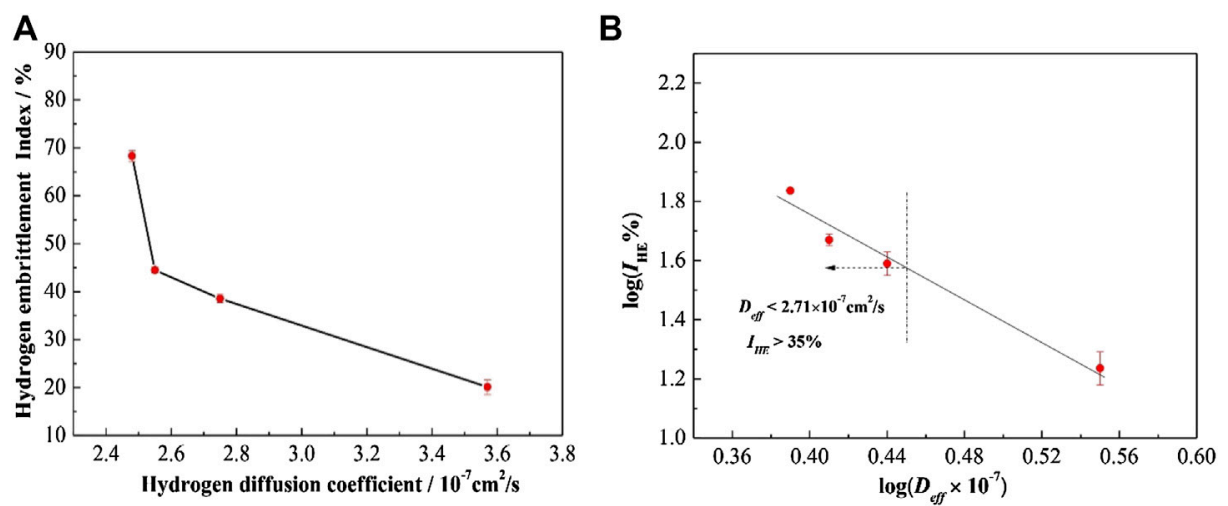

FIGURE 14 | Effect of the hydrogen diffusion coefficient on the embrittlement index of DP steels: (A) experimental dates; and (B) logarithmic values.

\section{Correlation Between Hydrogen Diffusion and Hydrogen Embrittlement in DP Steels}

The relationship between the $D_{\text {eff }}$ and the $I_{\mathrm{HE}}$ is established in Figure 14A and the logarithmic value of the coordinate variables is taken in Figure 14B. The mathematical relationship between them could be expressed in Eq. 10. It showed that $I_{\mathrm{HE}}$ increased with a decrease in $D_{\text {eff. }}$

$$
\log \left(I_{\mathrm{HE}}\right)=3.13-3.54 \times \log \left(D_{\text {eff }}\right)
$$

Previous studies have shown that the influence of hydrogen diffusion on hydrogen embrittlement is mainly related to the aggregation of hydrogen atoms in hydrogen traps (Davies, 1981; Liu et al., 2016a). When $D_{\text {eff }} \rightarrow 0$, hydrogen atoms were captured by hydrogen traps such as martensite and $\mathrm{F} / \mathrm{M}$ interface in DP steel, $I_{\mathrm{HE}}$ reached the maximum. With the increase of $D_{\text {eff, the concentration of hydrogen atoms }}$ captured by the hydrogen traps decreased and less hydrogen enriched at the martensite phase and $\mathrm{F} / \mathrm{M}$ interface, thus the hydrogen embrittlement susceptibility $I_{\mathrm{HE}}$ decreased. When $D_{\text {eff }}$ reached infinity, the concentration of hydrogen captured in the hydrogen traps is almost zero, which results that the $I_{\mathrm{HE}}$ approached zero. Previous study has shown that when $I_{\mathrm{HE}}$ is over $35 \%$, the material was sensitive to hydrogen embrittlement (Jahanara et al., 2019). We substituted 35\% into Eq. 10, $D_{\text {eff }}$ was calculated as $2.71 \times 10^{-7} \mathrm{~cm}^{2} / \mathrm{s}$. The $D_{\text {eff }}$ value could be used to evaluate hydrogen embrittlement susceptibility of DP steels and the material was sensitive to hydrogen embrittlement when the $D_{\text {eff }}$ was less than $2.71 \times 10^{-7} \mathrm{~cm}^{2} / \mathrm{s}$, which would need fewer test materials and shorter test time compared with the usual slow strain rate tensile test.

Through the above research, the hydrogen embrittlement problem in high strength steel is mainly caused by the trapping and aggregation of hydrogen atoms at the hydrogen traps such as ferrite/martensite interfaces or within the martensite phases. Therefore, during the development of new hydrogen resistant materials, reducing the number of hydrogen traps or the concentration of trapped hydrogen atoms can reduce the hydrogen embrittlement susceptibility of high strength steels containing martensite phase. The required strength of steel could be achieved by refining the grains if the quantity of martensite content were decreased to reduce the quantity of available hydrogen traps, such as martensite and ferrite/ martensite phase boundaries. Besides, the distribution of the martensite phases can be refined through suitable heat treatments to avoid the formation of a continuous martensite network.

\section{CONCLUSION}

(1) In DP steels, the hydrogen trapping density increases with increasing martensite content, resulting in an increase in hydrogen aggregation concentration and hydrogen embrittlement susceptibility. When the martensite content reaches $68.3 \%$ and distributes to a continuous network, the decreasing length of the ferrite/martensite interface makes it easier for gathering hydrogen atoms to reach the critical concentration for the cracking of the ferrite/martensite boundary, resulting in the continuously increasing of hydrogen embrittlement.

(2) The hydrogen diffusion is strongly influenced by the distribution of the martensite phases in DP steel. When the martensite phases are isolated, the diffusion of hydrogen primarily occurs through ferrite grains and the ferrite/martensite interfaces are the main traps that decrease the effective hydrogen diffusion coefficient with increasing martensite content. When the martensite phase starts to form a continuous network, the hydrogen atoms have to diffuse through the martensite phases. The counterbalancing effect of the increasing hydrogen diffusion coefficient in the martensite phase with decreasing carbon content slows the decrease of $D_{\text {eff. }}$.

(3) A logarithmic relationship between the hydrogen embrittlement index $I_{\mathrm{HE}}$ and the hydrogen diffusion coefficient $D_{\text {eff }}$ is established as $\log \left(I_{\mathrm{HE}}\right)=3.13-3.54 \times \log \left(D_{\mathrm{eff}}\right)$. The susceptibility of the hydrogen embrittlement in high strength DP steel will decrease with an increasing hydrogen diffusion coefficient. Finely dispersed 
martensite is conducive to reducing the hydrogen embrittlement susceptibility of DP steels with fewer hydrogen traps and a lower concentration of captured hydrogen atoms compared with martensite distribution in a continuous network.

\section{DATA AVAILABILITY STATEMENT}

The original contributions presented in the study are included in the article/Supplementary Material, further inquiries can be directed to the corresponding author.

\section{REFERENCES}

Chen, Y., Liu, J., Huang, F., Chen, L., Su, Y. J., and Zhou, G. F. (2019). Influence of inclusions on hydrogen-induced delayed cracking in hot stamping steels. J. Iron Steel Res. Int. 26, 1199-1208. doi:10.1007/s42243-019-00312-z

Davies, R. (1981). Hydrogen embrittlement of dual-phase steels. Metall. Trans. A 12, 1667-1672. doi:10.1007/bf02643572

Davies, R. (1983). Influence of martensite content on the hydrogen embrittlement of dual-phase steels. Scripta Metall. 17, 889-892. doi:10.1016/0036-9748(83) 90255-7

Frappart, S., Feaugas, X., Creus, J., Thebault, F., Delattre, L., and Marchebois, H. (2012). Hydrogen solubility, diffusivity and trapping in a tempered $\mathrm{Fe}-\mathrm{C}-\mathrm{Cr}$ martensitic steel under various mechanical stress states. Mater. Sci. Eng. A 534, 384-393. doi:10.1016/j.msea.2011.11.084

Geng, W. T., Wang, V., Li, J. X., Ishikawa, N., Kimizuka, H., Tsuzaki, K., et al. (2018). Hydrogen trapping in carbon supersaturated $\alpha$-iron and its decohesion effect in martensitic steel. Scripta Mater. 149, 79-83. doi:10.1016/j.scriptamat. 2018.02.025

Hadžipašić, A. B., Malina, J., and Malina, M. (2011a). The influence of microstructure on hydrogen diffusion and embrittlement of multiphase finegrained steels with increased plasticity and strength. Chem. Biochem. Eng. Q. 25 (2), 159-169.

Hadžipašić, A. B., Malina, J., and Nižnik, Š. (2011b). The influence of microstructure on hydrogen diffusion in dual phase steel. Acta Metall. Slovaca. 17, 129-137.

Hui, W. J., Wang, Z. H., Xu, Z. B., Zhang, Y. J., and Zhao, X. L. (2019). Hydrogen embrittlement of a microalloyed bainitic forging steel. J. Iron Steel Res. Int. 26, 1011-1021. doi:10.1007/s42243-019-00272-4

Jahanara, A. H., Mazaheri, Y., and Sheikhi, M. (2019). Correlation of ferrite and martensite micromechanical behavior with mechanical properties of ultrafine grained dual phase steels. Mater. Sci. Eng. 764, 138206. doi:10.1016/j.msea.2019. 138206

Khan, M. I., Kuntz, M. L., Biro, E., and Zhou, Y. X. (2008). Microstructure and mechanical properties of resistance spot welded advanced high strength steels. Mater. Trans. 49, 1629-1637. doi:10.2320/matertrans.mra2008031

Koyama, M., Tasan, C. C., Akiyama, E., Tsuzaki, K., and Raabe, D. (2014). Hydrogen-assisted decohesion and localized plasticity in dual-phase steel. Acta Mater. 70, 174-187. doi:10.1016/j.actamat.2014.01.048

Kumamoto, T., Koyama, M., Sato, K., and Tsuzaki, K. (2019). Strain-rate sensitivity of hydrogen-assisted damage evolution and failure in dual-phase steel: from vacancy to micrometer-scale void growth. Eng. Fract. Mech. 216, 106513. doi:10.1016/j.engfracmech.2019.106513

Li, Y. X., Lin, Z. Q., Jiang, A. Q., and Chen, G. L. (2003). Use of high strength steel sheet for lightweight and crashworthy car body. Mater. Des. 24, 177-182. doi:10.1016/s0261-3069(03)00021-9

\section{AUTHOR CONTRIBUTIONS}

ZW wrote the manuscript. All authors discussed the results and contributed the final manuscript.

\section{ACKNOWLEDGMENTS}

This work was supported by the National Natural Science Foundation of China (Grant no. 51871171 and 51871172). The authors would like to extend their gratitude to Bing $\mathrm{Fu}$, Xuan Zhang, and Lin Cheng from the School of Materials Science and Engineering.

Liu, Q., Venezuela, J., Zhang, M., Zhou, Q., and Atrens, A. (2016a). Hydrogen trapping in some advanced high strength steels. Corrosion Sci. 111, 770-785. doi:10.1016/j.corsci.2016.05.046

Liu, Q., Zhou, Q., Venezuela, J., Zhang, M., Wang, J., and Atrens, A. (2016b). A review of hydrogen embrittlement of martensitic advanced high-strength steels. Corrosion Rev. 34, 127-152. doi:10.1515/corrrev-2016-0006

Liu, Q., Zhou, Q., Venezuela, J., Zhang, M., and Atrens, A. (2018). The role of the microstructure on the influence of hydrogen on some advanced high-strength steels. Mater. Sci. Eng. A 715, 370-378. doi:10.1016/j.msea.2017.12.079

Loidl, M., Kolk, O., Veith, S., and Göbel, T. (2011). Characterization of hydrogen embrittlement in automotive advanced high strength steels. Mater. Werkst. 42, 1105-1110. doi:10.1002/mawe. 201100917

Ohmisawa, T., Uchiyama, S., and Nagumo, M. (2003). Detection of hydrogen trap distribution in steel using a microprint technique. J. Alloys Compd. 356, 290-294. doi:10.1016/s0925-8388(03)00355-4

Owczarek, E., and Zakroczymski, T. (2000). Hydrogen transport in a duplex stainless steel. Acta Mater. 48, 3059-3070. doi:10.1016/s1359-6454(00)00122-1

Robertson, I. M., Sofronis, P., Nagao, A., Martin, M. L., Wang, S., Gross, D. W., et al. (2015). Hydrogen embrittlement understood. Metall. Mater. Trans. A 46, 2323-2341. doi:10.1007/s11663-015-0325-y

Sirinakorn, T., Wongwises, S., and Uthaisangsuk, V. (2014). A study of local deformation and damage of dual phase steel. Mater. Des. 64, 729-742. doi:10. 1016/j.matdes.2014.08.009

Sun, S., Gu, J., and Chen, N. (1989). The influence of hydrogen on the sub-structure of the martensite and ferrite dual-phase steel. Scripta Mater. 23, 1735-1737. doi:10.1016/0036-9748(89)90352-9

Xia, Y. M., and Zhou, Y. X. (2000). The effect of strain rate and martensite volume fraction on tensile impact behavior of dual phase steels. Key Eng. Mater. 177, 231-236. doi:10.4028/www.scientific.net/kem.177-180.231

Yuan, W., Huang, F., Liu, J., Hu, Q., and Frank Cheng, Y. (2018). Effects of temperature and applied strain on corrosion of X80 pipeline steel in chloride solutions. Corrosion Eng. Sci. Technol. 53, 393-402. doi:10.1080/1478422X.2018.1491111

Zhang, T., Chu, W., Gao, K., and Qiao, L. (2003). Study of correlation between hydrogen-induced stress and hydrogen embrittlement. Mater. Sci. Eng. A 347, 291-299. doi:10.1016/s0921-5093(02)00600-7

Conflict of Interest: The authors declare that the research was conducted in the absence of any commercial or financial relationships that could be construed as a potential conflict of interest.

Copyright (C) 2020 Wang, Liu, Huang, Bi and Zhang. This is an open-access article distributed under the terms of the Creative Commons Attribution License (CC BY). The use, distribution or reproduction in other forums is permitted, provided the original author(s) and the copyright owner(s) are credited and that the original publication in this journal is cited, in accordance with accepted academic practice. No use, distribution or reproduction is permitted which does not comply with these terms. 